\title{
Effectiveness of salmeterol versus ipratropium bromide on exertional dyspnoea in COPD
}

\author{
M.L. Ayers*, R. Mejia", J. Ward*, T. Lentine*, D.A. Mahler*
}

Effectiveness of salmeterol versus ipratropium bromide on exertional dyspnoea in COPD. M.L. Ayers, R. Mejia, J. Ward, T. Lentine, D.A. Mahler. (C)ERS Journals Ltd 2001.

ABSTRACT: The hypothesis of the study was that salmeterol and ipratropium would have similar dyspnoea ratings during steady-state cycle ergometry at $1 \mathrm{~h}$, but that salmeterol would reduce dyspnoea at $6 \mathrm{~h}$ after administration in patients with chronic obstructive pulmonary disease (COPD).

The study design was a randomized, double-blind trial in 16 patients (aged $63 \pm 11$ yrs) with symptomatic COPD. Two days after familiarization with testing procedures, patients were randomly assigned to receive either two puffs $(42 \mu \mathrm{g})$ of salmeterol and two puffs of placebo inhaler, or two puffs $(36 \mu \mathrm{g})$ of ipratropium from each of two inhalers (total, $72 \mu \mathrm{g}$ ). Two days later, patients received the alternative medication. During exercise at $60 \%$ of peak oxygen consumption patients rated dyspnoea and performed inspiratory capacity manoeuvres each minute.

Forced expiratory volume in one second was $1.13 \pm 0.48 \mathrm{~L}(37 \pm 13 \%$ predicted). Dyspnoea ratings were similar for salmeterol and ipratropium at 1 and $6 \mathrm{~h}$. Inspiratory capacity was similar for salmeterol and ipratropium at $1 \mathrm{~h}$, but significantly higher for salmeterol at $6 \mathrm{~h}(\Delta=120 \mathrm{~mL} ; \mathrm{p}=0.03)$

It is concluded that with the doses used, salmeterol and ipratropium provided similar dyspnoea ratings during exercise at 1 and $6 \mathrm{~h}$ after administration.

Eur Respir J 2001; 17: 1132-1137.
*Section of Pulmonary and Critical Care Medicine, Dept of Medicine, Dartmouth Medical School, Lebanon. \# National Institute of Respiratory Disease, Mexico City, Mexico.

Correspondence: D.A. Mahler, Pulmonary \& Critical Care Medicine, 3-D, Dartmouth-Hitchcock Medical Center, One Medical Center Drive, Lebanon, NH 03756-000.

Fax: 9616036504437

Keywords: Bronchodilator therapy dyspnoea ratings

inspiratory capacity

Received: October 122000

Accepted after revision February 12 2001

Study was supported by a grant from GlaxoWellcome Inc.
Bronchodilator medications are prescribed to improve expiratory airflow and to reduce symptoms in patients with chronic obstructive pulmonary disease (COPD). The traditional approach to evaluate the response to bronchodilator therapy has been to examine the improvement in lung function, particularly forced expiratory volume in one second (FEV1), as the most comprehensive physiological test $[1-4]$. Over the past decade, investigators have shown that patients with COPD develop dynamic hyperinflation (DH) during exertion, which can contribute to dyspnoea [5-7].

At the present time, only two studies have examined the effects of bronchodilator therapy on DH and its possible role in the relief of exertional dyspnoea. In 1996, Belman et al. [8] found that three puffs of inhaled salbutamol reduced exercise $\mathrm{DH}$ and improved neuroventilatory coupling (the relationship of inspiratory effort and the resultant mechanical response) as well as exertional breathlessness in 13 patients with COPD. In 1998, O'DonNell et al. [9] showed that $500 \mu \mathrm{g}$ of nebulized ipratropium bromide improved exercise endurance time and inspiratory capacity (IC), as well as reduced the slope of dyspnoea ratings over time, compared with placebo.

Although comparison of a bronchodilator medication with placebo can demonstrate efficacy, a more relevant consideration is direct head-to-head comparison with another bronchodilator in order to examine effectiveness. The purpose of the present study was to compare the acute effects of salmeterol (S), an inhaled long-acting $\beta_{2}$-adrenergic bronchodilator, with ipratropium bromide (IB), an inhaled anticholinergic bronchodilator, on exertional breathlessness. Both medications have been recommended as maintenance therapy in the treatment of symptomatic COPD [1, 10, 11]. The hypothesis of the study was that $\mathrm{S}$ and IB would similarly reduce dyspnoea during steady-state cycle ergometry at $1 \mathrm{~h}$, but that $\mathrm{S}$ would provide a greater reduction at $6 \mathrm{~h}$ after administration. To investigate the effects of these medications on $\mathrm{DH}$ and its impact on the sensation of dyspnoea, the patients perfomed IC manoeuvres during exercise after both S and IB therapy.

\section{Materials and methods}

\section{Study subjects}

Patients were recruited from the outpatient clinics at the authors institution (Dartmouth Medical School, Lebanon). The following inclusion criteria were used: $40-80$ yrs of age; a diagnosis of COPD as defined by the American Thoracic Society [1]; an FEV1/forced vital capacity (FVC) ratio of $\leqslant 70 \%$; and dyspnoea on 
exertion. Exclusion criteria were: inability to tolerate temporary discontinuation of bronchodilator medications prior to each visit; inability to exercise on the cycle ergometer; an unstable respiratory status within the previous 4 weeks; any clinically significant comorbid disease; presence of an active infection; $>10 \mathrm{mg} \cdot \mathrm{day}^{-1}$ of prednisone; and a change in the dose of inhaled corticosteroid in the past month. The study was approved by the Institution Review Board and each patient provided written consent.

\section{Study design}

The study was a randomized, double-blind trial. At visit 1 , patients were familiarized with the testing procedures. At visit 2 (2-3 days later), each patient was randomly assigned by alternating order to receive either inhaled $\mathrm{S}$ or inhaled IB prior to testing. At visit 3 (2-3 days later), the patients received the alternative medication. Prior to any testing at all three visits, patients were instructed not to use short-acting inhaled bronchodilators for $8 \mathrm{~h}$, and long-acting bronchodilators for $24 \mathrm{~h}$. All testing was started by 08:00 - 08:30 h at all three visits. At visits 2 and 3 the sequence of testing was spirometry, measurement of $\mathrm{IC}$ and lung volumes before and $1 \mathrm{~h}$ after inhalation of the study bronchodilator, and then exercise testing. The same sequence was used at $6 \mathrm{~h}$ after inhalation of the study medication.

\section{Methods}

Visit 1. The purpose of visit 1 was for practice and familiarization with the technique. Spirometry, IC, and single-breath carbon monoxide diffusing capacity $(D \mathrm{~L}, \mathrm{CO})$ were measured using the SensorMedics 2200 testing system (Yorba Linda, CA, USA). Lung volumes were then measured by body plethysmography (SensorMedics). Patients were seated on an electronically-braked cycle ergometer (ErgoMetrics 800S, ErgoLine, Bitz, Germany) and practiced performing IC manoeuvres while cycling at no work load. The following written and verbal instructions were given: "At the end of a normal breath out, take a full, deep inspiration". The practice sessions took about 5-10 min until each subject was able to produce consistent IC values. During a 10 -min rest period, each patient read the following instructions regarding the $0-10$ category-ratio (CR-10) scale [12]: "This is a scale for rating breathlessness. The number 0 represents no breathlessness. The number 10 represents the strongest or greatest breathlessness that you have ever experienced. Each minute during the exercise test you will be asked to point to a number with your finger which represents your perceived level of breathlessness at that time. Use the written description to the right of the number to help guide your selection. I will say the number out loud to confirm your choice. During the exercise test you may have an even stronger or greater intensity of breathlessness than you have ever experienced. You should then point to the word 'maximal' if the severity is greater than 10. You can tell us the number after the mouthpiece has been removed".

While seated on the cycle ergometer, each subject breathed ambient air through a mouthpiece and a hot wire pneumotachygraph. Expired gas was analysed for minute ventilation $\left(V^{\prime} \mathrm{E}\right)$, oxygen consumption $\left(V^{\prime} \mathrm{O}_{2}\right)$, and carbon dioxide production $\left(V^{\prime} \mathrm{CO}_{2}\right)$ using breath-by-breath analysis from the $\left(V_{\max }\right)$ system (SensorMedics). After a 5-min equilibration period, the patients started exercise at zero load at a pedal speed of 50 revolutions per minute (rpm). After $1 \mathrm{~min}$, a load of $12.5 \mathrm{~W} \cdot \mathrm{min}^{-1}$ was applied, and thereafter increased by $12.5 \mathrm{~W} \cdot \mathrm{min}^{-1}$ every minute until the patient reached exhaustion or stopped because of symptom limitation. At each minute the patient was asked to rate the intensity of dyspnoea on the CR-10 scale. There was continuous monitoring of 12-lead electrocardiography (ECG) and oxygen saturation by pulse oximetry (Oxyshuttle; SensorMedics).

After a 30 min rest each participant performed steady-state exercise at $\sim 60 \%$ of peak $V^{\prime} \mathrm{O}_{2}$ for $10 \mathrm{~min}$. Expired gases, ECG, and oximetry were measured continuously as described for the incremental exercise test. After steady-state was achieved (first $5 \mathrm{~min}$ of exercise) the patient gave a rating of breathlessness at $40 \mathrm{~s}$ after the start of each minute (min 6-10) and was then instructed to perform an IC manoeuvre. The flow/volume loop was visualized by one of the investigators to verify that the start of each IC manoeuvre occurred at a consistent end-expiratory lung volume (EELV) and reached the expected endinspiratory lung volume (EILV) as previously determined on a maximal flow/volume loop at rest which was displayed on the monitor. Prior to and upon completion of the study, the accuracy of the IC values using the $V \max$ system during steady-state exercise was confirmed with measurements using a pneumotachygraph system.

Visit 2 (2-3 days later). After initial measurements each patient was randomly assigned to receive two puffs $(42 \mu \mathrm{g})$ of salmeterol and two puffs of an identical appearing placebo inhaler or two puffs $(36 \mu \mathrm{g})$ of ipratropium bromide from each of two inhalers (total, $72 \mu \mathrm{g}$ ). All patients were familiar with use of a metered-dose inhaler (MDI) and had demonstrated an appropriate technique at visit 1 . The following instructions were provided: "breathe out normally; put your mouth around the end of the inhaler; as you start to breathe in, actuate the inhaler and breathe in the spray with a slow, deep breath; hold your breath for up to $10 \mathrm{~s}$; wait one minute and repeat the process".

One of the investigators observed each patient inhale the study medication. At both 1 and $6 \mathrm{~h}$ after inhalation of the study medication each patient performed the following tests: spirometry, IC, lung volumes, and then steady-state exercise on the cycle ergometer for $10 \mathrm{~min}$. The same instructions and testing procedures were used as described at visit 1 .

Visit 3 (2-3 days later). Baseline FEV1 was required to be within $\pm 5 \%$ of the value at visit 2 . Patients returned for similar testing as described for visit 2 
Table 1.-Baseline characteristics of the subjects

\begin{tabular}{lc}
\hline Subjects n & 16 \\
Sex M:F & $9: 7$ \\
Age yrs & $63 \pm 11$ \\
Weight kg & $81 \pm 18$ \\
Height cm & $170 \pm 9$ \\
Lung function & $1.13 \pm 0.48(37 \pm 13)$ \\
FEV1 L & $3.01 \pm 0.92(77 \pm 14)$ \\
FVC L & $37 \pm 9$ \\
FEV $/$ FVC \% & $7.50 \pm 1.80(124 \pm 22)$ \\
TLC L & $5.71 \pm 1.43(175 \pm 38)$ \\
FRC L & $4.48 \pm 1.35(210 \pm 66)$ \\
RV L & $2.00 \pm 0.74$ \\
IC L & $95 \pm 2$ \\
Oxygenation & \\
$S_{\text {a, }} \mathrm{O}_{2} \%$ & $1.13 \pm 0.50(48 \pm 15)$ \\
Exercise performance & $76.4 \pm 29.0$ \\
Peak $V \mathrm{O}_{2} 1 \cdot$ min $^{-1}$ & $40.4 \pm 21.1(88 \pm 19)$ \\
Peak power watts & $128 \pm 24(76 \pm 14)$ \\
Peak $V$ E $1 \cdot$ min $^{-1}$ & \\
Peak heart rate beats $\cdot \mathrm{min}^{-1}$ & $6.3 \pm 2.5$ \\
Peak ratings $(0-10)$ & $5.3 \pm 2.7$ \\
$\quad$ Dyspnoea & \\
$\quad$ Leg discomfort &
\end{tabular}

Values are presented as mean $\pm \mathrm{SD}$; values in parenthesis represent per cent of the predicted value. FEV1: forced expiratory volume in one second; FVC: force vital capacity; TLC: total lung capacity; FRC: functional residual capacity; $\mathrm{RV}$ : residual volume; IC: inspiratory capacity; $\mathrm{Sa}_{\mathrm{a}} \mathrm{O}_{2}$ : arterial oxygen saturation; $V_{\mathrm{O}_{2}}$ : oxygen consumption; $V \mathrm{E}$ : minute ventilation.

except they received the alternative medication. Predicted values for lung function were taken from CRAPO et al. [13].

\section{Calculations}

STubBing et al. [14] have shown that total lung capacity (TLC) does not change during exercise in patients with COPD. Accordingly, EELV was calculated by subtracting IC from TLC. EILV was determined by adding exercise tidal volume to EELV.

\section{Statistical analysis}

The major outcome of the study was ratings of dyspnoea during exercise. Values at visits 2 and 3 at respective time periods were compared using the paired t-test for FEV1 and lung volumes and analysis of variance for multiple comparisons (MANOVA) for selected variables during steady-state exercise. Correlations among various physiological variables and dyspnoea ratings were made using the Spearman rank order correlation test.

It was calculated that 16 patients were required to have $80 \%$ power to detect a mean difference between subjects of 1 unit on the CR-10 scale at an alpha of 0.05 (two-sided) based on a standard deviation of 1 unit. A p-value $<0.05$ was considered as significant.

\section{Results}

\section{Subjects}

Of the 17 patients recruited for the study, 16 completed testing. One subject withdrew from the study after visit 1 because of an acute respiratory infection. Baseline characteristics of the subjects are listed in table 1.

\section{Lung function}

There were no significant differences for spirometry, IC, and lung volumes at baseline testing at visits 1, 2 , and 3. Values for these physiological variables at 1 and $6 \mathrm{~h}$ after inhalation of the study medication are shown in table 2 . For both S and IB there were significant increases in FEV1, FVC, and IC at 1 and $6 \mathrm{~h}$ and significant decreases in FRC and residual volume (RV) at 1 and $6 \mathrm{~h}$. Direct comparisons between the two medications showed no significant differences in any of these measures.

\section{Exercise responses}

Values for dyspnoea ratings and for selected physiological variables during min $6-10$ of steady-state exercise are shown in table 3 . These data indicate that the exercise intensity and the major cardiorespiratory responses were nearly identical during exercise with bronchodilator therapies. Of note, heart rate (HR)

Table 2. - Values for forced expiratory volume in one second (FEV1) and lung volumes at rest after bronchodilator therapy

\begin{tabular}{|c|c|c|c|c|c|c|c|c|}
\hline & \multicolumn{4}{|c|}{1 hour } & \multicolumn{4}{|c|}{6 hour } \\
\hline & $\mathrm{S}$ & IB & $\begin{array}{c}\text { Mean }(95 \% \mathrm{CI}) \\
\text { diff.* }\end{array}$ & -value & $\mathrm{S}$ & IB & $\begin{array}{c}\text { Mean }(95 \% \mathrm{CI}) \\
\text { diff.* }\end{array}$ & -value \\
\hline FEV1 & $1.36 \pm 0.50$ & $1.33 \pm 0.47(18)$ & $0.03(-0.07-0.13)$ & 0.53 & $1.36 \pm 0.58(20)$ & $1.25 \pm 0.48$ & $0.11(-0.06-0.30)$ & 0.19 \\
\hline $\mathrm{FVC}$ & $3.48 \pm 1.01(16)$ & $3.55 \pm 0.91(18)$ & $-0.07(-0.17-0.05)$ & 0.24 & $3.46 \pm 1.09$ (15) & $3.23 \pm 0.88(7)$ & $0.23(-0.02-0.47)$ & 0.07 \\
\hline TLC & $7.34 \pm 1.63(-2)$ & $7.27 \pm 1.62(-4)$ & $0.07(-0.05-0.20)$ & 0.24 & $7.48 \pm 1.59(0)$ & $7.38 \pm 1.66(-2)$ & $0.10(-0.05-0.25)$ & 0.17 \\
\hline FRC & $5.22 \pm 1.20(-9)$ & $5.04 \pm 1.35(-12)$ & $0.18(-0.01-0.38)$ & 0.07 & $5.11 \pm 1.21(-11)$ & $5.20 \pm 1.45(-9)$ & $-0.09(-0.38-0.21)$ & 0.54 \\
\hline RV & $3.81 \pm 1.07(-15)$ & $3.73 \pm 1.16(-17)$ & $0.08(-0.08-0.24)$ & 0.31 & $3.92 \pm 1.02(-13)$ & $4.07 \pm 1.17(-9)$ & $-0.15(-0.40-0.12)$ & 0.27 \\
\hline IC & $2.12 \pm 0.56(6)$ & $2.23 \pm 0.51(12)$ & $-0.11(-0.37-0.14)$ & 0.11 & $2.37 \pm 0.55$ (19) & $2.18 \pm 0.63(9)$ & $0.19(-0.21-0.28)$ & 0.77 \\
\hline
\end{tabular}

Data are presented as mean \pm SD (\% change from premedication values). S: salmeterol; IB: ipratropium bromide; CI: confidence interval. FVC: force vital capacity; TLC: total lung capacity; FRC: functional residual capacity; RV: residual volume; IC: inspiratory capacity; *: mean differences between S and IB. The paired t-test was used to compare S and IB at 1 and $6 \mathrm{~h}$. 
Table 3. - Values for selected variables during steady-state exercise

\begin{tabular}{|c|c|c|c|c|c|c|}
\hline \multirow[t]{2}{*}{ Parameter } & \multicolumn{3}{|c|}{1 hour } & \multicolumn{3}{|c|}{6 hour } \\
\hline & $\mathrm{S}$ & IB & $\begin{array}{c}\text { Mean }(95 \% \mathrm{CI}) \& \\
\text { the difference } \\
\text { between S and IB }\end{array}$ & $\mathrm{S}$ & IB & $\begin{array}{l}\text { Mean }(95 \% \mathrm{CI}) \& \\
\text { the difference } \\
\text { between S and IB }\end{array}$ \\
\hline Work watts & $25+15$ & $25+15$ & $0.0(0.0-0.0)$ & $25+15$ & $25+15$ & $0.0(-0.9-0.4)$ \\
\hline$V \mathrm{O}_{2} \mathrm{~L} \cdot \min ^{-1}$ & $0.65 \pm 0.23$ & $0.65 \pm 0.24$ & $0.00(-0.05-0.05)$ & $0.67 \pm 0.23$ & $0.64 \pm 0.20$ & $0.03(-0.01-0.06)$ \\
\hline $\mathrm{HR}$ beats $\cdot \min ^{-1}$ & $101 \pm 18$ & $95 \pm 17^{\#}$ & $6.0(1.1-10.9)$ & $101 \pm 14$ & $101 \pm 15$ & $0.0(-4.8-4.8)$ \\
\hline$V \mathrm{E} \mathrm{L} \cdot \min ^{-1}$ & $26 \pm 8$ & $26 \pm 8$ & $0.0(-2.3-3.2)$ & $26 \pm 8$ & $24 \pm 6$ & $2.0(-0.5-3.1)$ \\
\hline Tidal volume $\mathrm{L}$ & $1.18 \pm 0.35$ & $1.18 \pm 0.32$ & $0.0(-0.09-0.08)$ & $1.12 \pm 0.33$ & $1.08 \pm 0.26$ & $0.04(-0.10-0.09)$ \\
\hline IC L & $2.03+0.65$ & $1.99+0.56$ & $0.04(-0.04-0.15)$ & $1.88+0.71$ & $1.76+0.55^{\circ}$ & $0.12(0.00-0.24)$ \\
\hline EILV L & $6.49 \pm 1.56$ & $6.47 \pm 1.56$ & $0.02(-0.08-0.17)$ & $6.57 \pm 1.45$ & $6.68 \pm 1.62$ & $-0.11(-0.16-0.26)$ \\
\hline EELV L & $5.31 \pm 1.38$ & $5.28 \pm 1.42$ & $0.03(-0.08-0.18)$ & $5.60 \pm 1.35$ & $5.62 \pm 1.53$ & $-0.02(-0.24-0.21)$ \\
\hline Dyspnoea $(0-10)$ & $2.0 \pm 1.3$ & $1.9 \pm 1.4$ & $0.1(-0.6-0.8)$ & $2.1 \pm 1.2$ & $2.2 \pm 1.2^{+}$ & $-0.1(-0.5-0.2)$ \\
\hline
\end{tabular}

Values are presented as mean $+\mathrm{SD}$ during 5 min of steady-state exercise; $V \mathrm{O}_{2}$ : oxygen consumption; HR: heart rate; $V \mathrm{E}$ : minute ventilation; IC: inspiratory capacity; EILV: end-inspiratory lung volume; EELV: end-expiratory lung volume; CI: confidence interval; S: salmeterol; IB: ipratropium bromide. Analysis of variance for multiple comparisons used to compare S and IB at 1 and $6 \mathrm{~h}$. ${ }^{\#}: \mathrm{p}=0.02$ for $\mathrm{S}>\mathrm{IB}$ at $1 \mathrm{~h} ;{ }^{\uparrow}: \mathrm{p}=0.03$ for $\mathrm{S}>\mathrm{IB}$ at $6 \mathrm{~h} ;{ }^{+}: \mathrm{p}=0.05$ for $\mathrm{S}<\mathrm{IB}$ at $6 \mathrm{~h}$; For all other comparisons between $\mathrm{S}$ versus $\mathrm{IB}, \mathrm{p}>0.05$.

response was higher with $\mathrm{S}\left(101 \pm 18\right.$ beats $\left.\cdot \mathrm{min}^{-1}\right)$ compared with IB $\left(95 \pm 17\right.$ beats $\left.\cdot \mathrm{min}^{-1}\right)$ at $1 \mathrm{~h}$ $(\mathrm{p}=0.02)$.

At both 1 and $6 \mathrm{~h}$, dyspnoea ratings were similar with the two medications, although statistical comparison showed borderline significance for $\mathrm{S}<\mathrm{IB}$ at $6 \mathrm{~h}(\mathrm{p}=0.05)$ (fig. 1a). Values for IC were similar with $\mathrm{S}$ and IB at $1 \mathrm{~h}$; at $6 \mathrm{~h}$ IC was significantly higher with $\mathrm{S}$ compared with IB $(\Delta=120 \mathrm{~mL} ; \mathrm{p}=0.03)$ (fig. 1b).

\section{Correlation analyses}

When considering data at 1 and $6 \mathrm{~h}$ with both medications at visits 2 and $3(n=64)$, dyspnoea ratings during steady-state exercise were significantly correlated with $\mathrm{IC}$ values $\left(\mathrm{r}_{\mathrm{s}}=-0.28 ; \mathrm{p}=0.03\right)$. However, there were no significant correlations between dyspnoea ratings during exercise and resting lung function or other exercise variables.

\section{Discussion}

The present results showed that two puffs $(42 \mu \mathrm{g})$ of $\mathrm{S}$ and four puffs $(72 \mu \mathrm{g})$ of IB provided similar dyspnoea ratings during steady-state exercise at both 1 and $6 \mathrm{~h}$ after administration. Furthermore, physiological variables during exercise were also comparable between the two bronchodilator medications, except for a higher IC with $\mathrm{S}$ than with IB at $6 \mathrm{~h}$ $(\Delta=120 \mathrm{~mL})$. However, the difference in the IC did not contribute to a corresponding reduction in breathlessness with $\mathrm{S}$.

Several factors in the design of the study were considered. In comparing a long-acting $\beta_{2}$-adrenergic agonist and an anticholinergic agent, generally accepted doses as used commonly in clinical practice were selected. For S, $42 \mu \mathrm{g}$ (two puffs) were used. Studies have shown no additional bronchodilator benefit with higher doses $[15,16]$. For IB, bromide $72 \mu \mathrm{g}$ (four
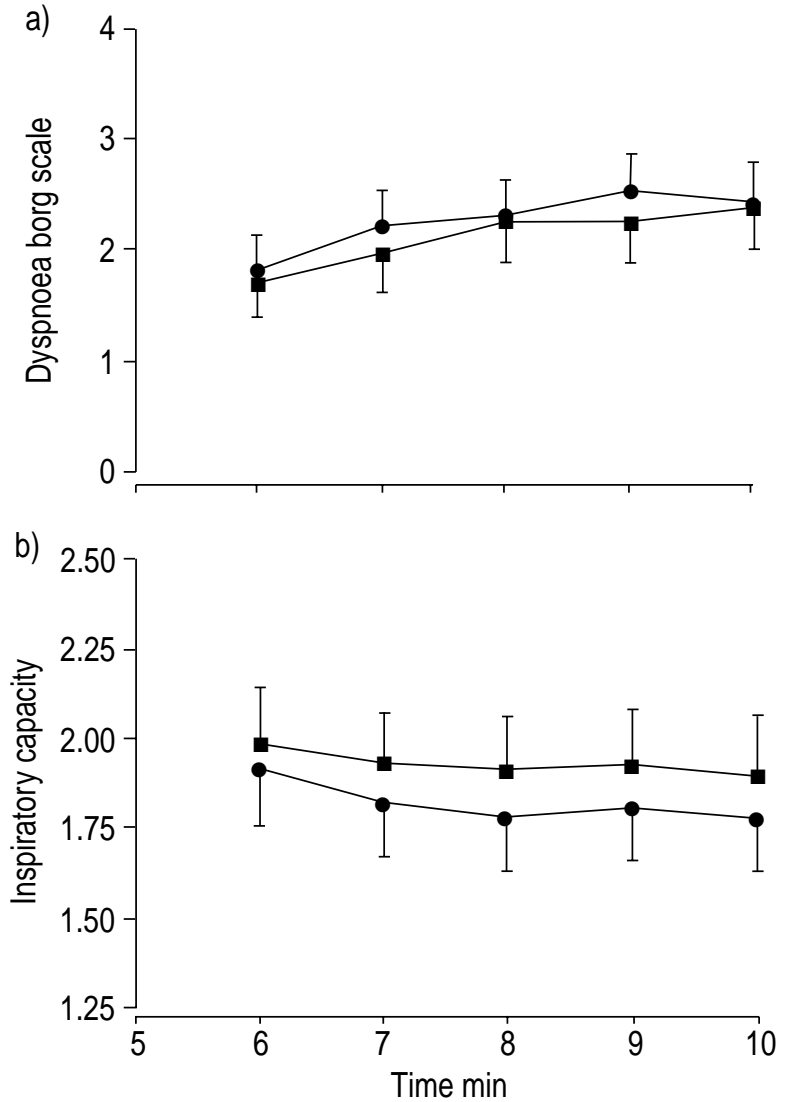

Fig. 1. - a) Dyspnoea ratings (mean \pm SD) at $6 \mathrm{~h}$ during min $6-10$ of steady-state exercise with salmeterol ( $\square$ ) and ipratropium bromide $(\bigcirc)$ for the 16 patients. Dyspnoea ratings were similar with the two medications, although statistical comparison showed borderline significance for salmeterol (S) less than ipratropium bromide (IB) $(\mathrm{p}=0.05)$. b) Values for inspiratory capacity (IC) in Litres at $6 \mathrm{~h}$ during $\min 6-10$ of steady-state exercise with $S(\boldsymbol{a})$ and IB ( for the 16 patients. IC was significantly higher with $\mathrm{S}$ compared with IB $(\mathrm{p}=0.03)$. 
puffs) were used. Although two puffs is considered the starting dose, higher doses are used frequently $[1,10]$. Thus, it was considered that four puffs of IB and two puffs of $\mathrm{S}$ would be a clinically relevant comparison. In fact, the changes in resting lung function were similar after $\mathrm{S}$ and for IB (table 2). Exertional breathlessness was chosen as the major outcome of the study because it is the most frequent complaint of patients with COPD. Furthermore, a preliminary report describing the objectives of the Global Initiative for Chronic Obstructive Lung Diseases (GOLD) emphasized a "symptom-driven approach" for treatment of this condition [17]. In addition to evaluation of dyspnoea in this study, the development of exercise $\mathrm{DH}$ as a potential factor contributing to exertional dyspnoea was also examined [6, 8, 9]. Thus, both dyspnoea ratings and IC were measured during exercise and the responses of these two bronchodilator medications compared.

However, a placebo arm was not included in the study design for two major reasons. Firstly, the hypothesis of the study addressed a head-to-head comparison of these maintenance bronchodilators at doses used in clinical practice in the treatment of COPD (i.e. effectiveness). Secondly, previous studies have shown that both $\mathrm{S}$ and IB reduce dyspnoea relative to placebo therapy $[9,11,18]$. For example, O'Donnell et al. [9] showed that nebulized IB decreased dyspnoea ratings and increased IC compared with placebo during submaximal exercise on the cycle ergometer. Therefore, inclusion of a placebo trial was considered not to be either necessary or important.

An additional consideration was the time period for examining the effects of the agents. BELMAN et al. [8] studied the immediate $(\sim 2 \mathrm{~h})$ effects of albuterol therapy and $\mathrm{O}^{\prime}$ DonNell et al. [9] performed testing before and $1 \mathrm{~h}$ after patients received nebulized IB or placebo, both at the beginning and at the end of an 8 -week study. However, $S$ has a 12 -h duration of action, whereas IB lasts $\sim 4-6 \mathrm{~h}$. Thus, in order to complete testing for each medication in a single day, these agents were compared at two time periods, at $1 \mathrm{~h}$, when the benefits might be similar, and at $6 \mathrm{~h}$ when $\mathrm{S}$ might provide greater effectiveness because of a longer duration of action.

As expected, both medications improved expiratory airflow (increased FEV1) and lung volumes (increased FVC and IC; decreased FRC and RV) at both time periods. The acute improvements in FEV1 and FVC observed with $\mathrm{S}$ and IB were similar to those observed by investigators in other studies [11, 18, 19]. Furthermore, the reductions in resting lung volumes (FRC and $\mathrm{RV}$ ) with $\mathrm{S}$ were comparable in magnitude to the changes observed by RAMIREZ-VENEGAS et al. [18] with $\mathrm{S}$ over a 4-h time period. Any decreases in lung hyperinflation with inhaled bronchodilator therapy should enable the patient to breathe with improved ventilatory mechanics [8, 9]. As such, the benefits should include reductions in: mechanical restriction; elastic threshold loading; and inspiratory pleural pressure swings [20, 21].

To investigate the possible role of $\mathrm{DH}$ as a mechanism contributing to the sensation of exertional breathlessness, the patients performed IC manoeuvres during steady-state exercise. At the initial visit, each patient practiced the IC manoeuvre firstly at rest and then during cycle ergometry. Steady-state exercise rather than incremental exercise was selected for three reasons. Firstly, the authors experience has been that patients with COPD can perform IC manoeuvres more consistently during submaximal, steady-state exercise as opposed to incremental exercise. Patients and healthy individuals may experience difficulty doing IC manoeuveres at high intensities of exercise due to the excessive physiological and subjective demands. Secondly, submaximal exercise is clearly more relevant to daily activities experienced by patients with COPD as opposed to incremental exercise to exhaustion. Thirdly, studies have demonstrated that steady-state exercise is more responsive to change with anticholinergic therapy in patients with severe COPD [9, 22].

Except for the slightly higher IC during exercise with $\mathrm{S}$ at $6 \mathrm{~h}(\mathrm{p}=0.03$ versus $\mathrm{IB})$, both bronchodilator agents otherwise provided comparable physiological and perceptual exercise responses. The actual values for IC during exercise in the present study were similar in magnitude to those observed after nebulized IB by O'DONNELl et al. [9], who had subjects exercise at $50-60 \%$ of the maximum work rate. Unfortunately, neither BELMAN et al. [8] or YAN et al. [7] reported actual IC values during exercise in patients with COPD.

Previous investigators have demonstrated the validity and utility of measuring IC during exercise to evaluate the development of $\mathrm{DH}$ in patients with COPD [5-9, 23]. In brief, $\mathrm{DH}$ can be determined noninvasively by having the subject perform successive IC manoeuvres during exercise. Based on the finding by STUBbing et al. [14] that TLC does not change during exertion in patients with COPD, an observed decrease in IC reflects an increase in EELV (i.e. $\mathrm{DH})[5,7,20]$. Although $\mathrm{DH}$ allows patients to generate greater expiratory flow, the consequences include shortening of the vertical muscle fibres of the diaphragm and an elastic load on the muscles during inspiration [20, 21]. Previous studies of inhaled bronchodilator therapy in patients with COPD have shown that even a modest reduction in $\mathrm{DH}$ may contribute to an improvement in dyspnoea [8, 9, 24].

Although a significant relationship between dyspnoea ratings and IC was observed during exercise, the correlation coefficient was low $\left(r_{S}=-0.28\right)$. O'Donnell et al. [9] observed a slightly higher, albeit modest correlation coefficient $(-0.35)$ among changes in the same parameters. These results suggest that although DH can contribute to exertional breathlessness in patients with COPD, additional physiological and/or sensory factors are also important to the perception of dyspnoea during exercise.

To the best of the authors' knowledge, only one previous study has compared the effects of S and IB on exertional dyspnoea and exercise responses in patients with COPD. In a previous study, PATAKAS et al. [25] compared $50 \mu \mathrm{g}$ (two puffs) of S and $120 \mu \mathrm{g}$ (six puffs) IB on breathlessness during treadmill exercise in 15 patients with COPD. The authors 
found that the distance walked increased significantly with both $\mathrm{S}$ and with IB, but the distance walked on the treadmill when patients had no breathlessness was increased with $\mathrm{S}(\mathrm{p}<0.05)$, but not with IB. PATAKAS et al. [25] concluded that the overall effects of these two medications were similar as related to the dyspnoea sensation during exercise. Thus, the present results both confirm and extend these observations on the effectiveness of S and IB.

In summary, at the doses used, salmeterol and ipratropium bromide had similar effects on both physiological and perceptual outcomes at 1 and $6 \mathrm{~h}$ after administration, at rest as well as during steadystate exercise. Previous studies have demonstrated the efficacy of salmeterol and ipratropium bromide on similar outcomes compared to placebo medication [9, 11, 18]. Although dynamic hyperinflation contributed, at least in part, to the severity of exertional dyspnoea in this study, other factors appear to be important in explaining the sensation of breathlessness in patients with chronic obstructive pulmonary disease.

\section{References}

1. American Thoracic Society. Standards for the diagnosis and care of patients with chronic obstructive pulmonary disease. Am J Respir Crit Care Med 1995; 152: S77-S120.

2. The COPD guidelines group of the the standards of care committee of theBTS. BTS guidelines for the management of chronic obstructive pulmonary disease. Thorax 1997; 52: Suppl. 5, S1-S28.

3. Wolkove N, Dajczman E, Colacone A, Kreisman H. The relationship between pulmonary function and dyspnea in obstructive lung disease. Chest 1989; 96 : $1247-1251$

4. Limauro J, Mahler DA, Olmstead EM, Tosteson ANA. Responses to inhaled bronchodilator in patients with acute airflow obstruction. Respir Care 1995; 40: $815-819$

5. Babb TG, Viggiano R, Hurley B, Staats B, Rodarte JR. Effect of mild-to-moderate airflow limitation on exercise capacity. J Appl Physiol 1991; 70: 223-230.

6. O'Donnell DE, Webb KA. Exertional breathlessness in patients with chronic airflow obstruction; the role of lung hyperinflation. Am Rev Respir Dis 1993; 148: $1351-1357$

7. Yan S, Kaminski D, Sliwinski P. Reliability of inspiratory capacity for estimating end-expiratory lung volume changes during exercise in patients with chronic obstructive pulmonary disease. Am J Respir Crit Care Med 1997; 156: 55-59.

8. Belman MJ, Botnick WC, Shin JW. Inhaled bronchodilators reduce dynamic hyperinflation during exercise in patients with chronic obstructive pulmonary disease. Am J Respir Crit Care Med 1996; 153: 967-975.

9. O'Donnell DE, Lam M, Webb KA. Measurement of symptoms, lung hyperinflation, and endurance during exercise in chronic obstructive pulmonary disease. Am J Respir Crit Care Med 1998; 158: 1557-1565.

10. Ferguson GT, Cherniack RM. Management of chronic obstructive pulmonary disease. $N$ Engl J Med 1993; 328: $1017-1022$.

11. Mahler DA, Donohue JF, Barbee RA, et al. Efficacy of salmeterol xinafoate in the treatment of COPD. Chest 1999; 115: 957-965.

12. Borg GAV. Psychophysical bases of perceived exertion. Med Sci Sports Exerc 1982; 14: 377-381.

13. Crapo RO, Morris AH, Gardner RM. Reference spirometric values using techniques and equipment that meet ATS recommendations. Am Rev Respir Dis 1981; 123: 659-664.

14. Stubbing DG, Pengelly LD, Morse JC, Jones NL. Pulmonary mechanics during exercise in subjects with chronic airflow obstruction. J Appl Physiol 1980; 49: $511-517$.

15. Boyd G, Morice AH, Pounsford JC, Siebert M, Peslis $\mathrm{N}$, Crawford C. An evaluation of salmeterol in the treatment of chronic obstructive pulmonary disease (COPD). Eur Respir J 1997; 10: 815-821.

16. Jones PW, Bosh TK. in association with an international study group. Quality of life changes in COPD patients treated with salmeterol. Am J Respir Crit Care Med 1997; 155: $1283-1289$.

17. Pauwels RA. National and International Guidelines for COPD: the need for evidence. Chest 2000; 117: $20 \mathrm{~S}-22 \mathrm{~S}$.

18. Ramirez-Venegas A, Ward J, Lentine T, Mahler DA. Salmeterol reduces dyspnea and improves lung function in patients with COPD. Chest 1997; 112: $336-$ 340 .

19. Braun SR, McKenzie WM, Copeland C, Knight L, Ellersieck M. A comparison of the effect of ipratropium and albuterol in the treatment of chronic obstructive airway disease. Arch Intern Med 1989; 149: $544-547$.

20. $\mathrm{O}^{\prime}$ Donnell DE. Exertional breathlessness in chronic respiratory disease. In: Mahler DA, ed. Lung Biology in Health and Disease. Vol. 111: Dyspnea. New York, Marcel Dekker, 1998; pp. $197-147$.

21. Younes M. Determinants of thoracic excursions during exercise. In: Whipp BJ, Wasserman K, eds. Lung Biology in Health and Disease. Vol. 52: Exercise Pulmonary Physiology and Pathophysiology. New York, Marcel Dekker, 1991; pp. 1-65.

22. Oga T, Nishimura K, Tsukino M, Hajiro T, Ikeda A, Izumi $\mathrm{T}$. The effects of oxitropium bromide on exercise performance in patients with stable chronic obstructive pulmonary disease. Am J Respir Crit Care Med 2000; 161: $1897-1901$.

23. Diaz O, Villafranca $\mathrm{C}$, Ghezzo $\mathrm{H}$, et al. Role of inspiratory capacity on exercise tolerance in COPD patients with and without expiratory flow limitation. Eur Respir J 2000; 16: 269-275.

24. Tantucci C, Duguet A, Similowski T, Zelter M, Derenne JP, Milic-Emili J. Effect of salbutamol on dynamic hyperinflation in chronic obstructive pulmonary disease patients. Eur Respir J 1998; 12: 799-804.

25. Patakas D, Andreadis D, Mavrofridis E, Argyropolou P. Comparison of the effects of salmeterol and ipratropium bromide on exercise performance and breathlessness in patients with stable chronic obstructive pulmonary disease. Respir Med 1998; 92: $1116-$ 1121. 